\title{
UPAYA MEMUTUS RANTAI INFEKSI MELALUI EDUKASI GOOD HAND HYGIENE PADA KELUARGA PENUNGGU PASIEN YANG DIRAWAT DI RUMAH SAKIT DR. SLAMET GARUT
}

\section{BREAKING CHAIN OF INFECTION THROUGH GOOD HAND HYGIENE EDUCATION FOR PATIENT'S CARETAKER AT DR. SLAMET GARUT HOSPITAL}

\author{
${ }^{1)}$ Iin Patimah, ${ }^{2)}$ Ai Hani, ${ }^{3)}$ Astrie Dewi, ${ }^{4)}$ Budi Setiawan, ${ }^{5}$ Devita Arumandana \\ ${ }^{1,2,3,4,5)}$ Program Studi Profesi Ners STIKes Karsa Husada Garut \\ Jln. Nusa Indah no. 24, Garut Jawa Barat \\ *Email: iin.patimah84@gmail.com
}

\begin{abstract}
ABSTRAK
Health Care Associated Infection (HAIs) adalah infeksi yang terjadi pada pasien rawat inap di pelayanan kesehatan. HAIs merupakan masalah yang umum ditemukan di berbagai rumah sakit, baik dalam negeri maupun luar negeri. HAIs berdampak pada penurunan kualitas layanan rumah sakit dan merugikan pada pasiennya sendiri. Oleh karena itu diperlukan pencegahan untuk mmutus rantai infeksi. Salah satu upaya pencegahan untuk memutus rantai infeksi yaitu dengan cara melakukan edukasi pada penunggu pasien untuk meningkatkan perilaku yang baik dalam memutus rantai infeksi. Tujuan dari kegiatan ini adalah untuk memberikan pengetahuan kepada keluarga penunggu pasien tentang pentingnya mencuci tangan dan mengetahui bagaimna langkah mencuci tangan. Metode yang digunakan adalah penyuluhan langsung bertatap muka dengan keluarga penunggu pasien melalui media power point dan leaflet serta evaluasi berupa instrument pengetahuan tentang cuci tangan yang berjumlah 10 pertanyaan. Hasil yang didapatkan menunjukkan bahwa, dari 20 peserta kegiatan, setelah dilakukan edukasi hand hygiene, 15 peserta menunjukkan pengetahuan yang baik (75\%) dan 5 orang (25\%) dalam kategori pengetahuan cukup. Diperlukan program edukasi yang berkesinambungan kepada setiap pengunjung rumah sakit.
\end{abstract}

Kata kunci: Cuci Tangan; HAIs; Infeksi; Nosokomial

\section{ABSTRACT}

Health Care Associated Infection (HAIs) is infections that occur in hospitalized patients in health services. HAIs is a common problem found in various hospitals, both domestic and international. HAIs affect the decreasing quality of hospital services and harm the patients themselves. Therefore, prevention is needed to break the chain of infection. One of the prevention efforts to break the chain of infection is by educating the patient's caretaker to improve good behavior in breaking the infection chain. This activity aims to provide knowledge to the families of patients waiting about the importance of washing their hands and knowing how to wash their hands. The method used is direct counseling with the patient's caretakers using PowerPoint media and leaflets as well as an evaluation in the form of an instrument of knowledge about handwashing totaling 10 questions. The results showed that, from the 20 participants, after hand hygiene education, 15 participants showed good understanding (75\%) and 5 people (25\%) in the category of sufficient understanding. A continuous education program is needed for every hospital visitor.

Keywords: Handwashing; HAIs; Infection; Nosocomial

Submitted : 21 Februari 2020 Revision : 21 Februari 2021 Accepted : 22 Maret 2021 


\section{PENDAHULUAN}

\section{Health Care Associated Infection} (HAIs) atau dikenal infeksi nosocomial merupakan permasalah serius yang dihadapi seluruh rumah sakit di dunia. HAIS berdampak pada meningkatnya biaya rawat inap, Length of Stay, morbiditas, serta mortalitas (Arefian et al., 2019). HAIs adalah infeksi yang dialami pasien selama pasien dirawat di pelayanan kesehatan baik itu di rumah sakit atau pelayanan kesehatan lainnya yang muncul dalam 48 jam setelah masuk rumah sakit atau 30 hari setelah menerima perawatan kesehatan (Haque, Sartelli, McKimm, \& Abu Bakar, 2018).

Kejadian HAIs di tahun 2016 mencapai $15 \%$ dari total pasien di seluruh dunia yang dilakukan rawat inap (WHO, 2016). Terdapat perbedaan kejadian HAIs antara Negara maju dan berkembang. Di negara-negara maju, kejadian HAIs berkisar di angka $5-10 \%$ di rumah sakit perawatan akut, sedangkan di negara berkembang, kejadian HAIs biasanya lebih tinggi dari $15 \%$. Lebih dari 4000 anak meninggal karena HAIs setiap hari, sekitar setengah dari semua pasien yang dirawat di unit perawatan intensif neonatal mendapatkan infeksi, dan lebih dari setengahnya meninggal dunia (WHO, 2019).

HAIs dapat terjadi melalui berbagai cara, salah satunya melalui infeksi silang (cross infection) (Haque et al., 2018), yaitu infeksi yang terjadi dari seseorang (petugas kesehatan, pasien lain, pengunjung, bahkan penjaga pasien) ke pasien yang sedang dirawat. Penjaga pasien beresiko sebagai carier (pembawa) atau sudah terkontaminasi bakteri yang berdampak menularkan ke pasien ataupun sebaliknya.

HAIs dapat dikendalikan secara efektif dengan memutus 6 mata rantai infeksi. HAIs terjadi karena adanya 6 komponen rantai infeksi yang terjalin satu sama lain, yang mana jika satu mata rantai diputus atau dihilangkan maka penularan infeksi dapat dicegah bahkan dapat dihentikan.

Upaya memutus mata rantai infeksi salah satunya dengan melakukan hand Hygiene (Emergencies, 2009). Tangan sebagai pembawa bakteri yang paling umum dapat menyebarkan mikroorganisme dari satu orang lain ke yang lain. Oleh karena itu, kebersihan tangan merupakan hal yang sangat penting untuk memutus rantai infeksi. Cara untuk mempertahankan agar mencegah transfer mikroorganisme melalui tangan yaitu dengan melalukan keberihan tangan (hand hygine). Cuci tangan wajib dilakukan pada 6 moment berikut ini: sebelum kontak dengan, sebelum tindakan aseptis, setelah tindakan aseptis, setelah kontak dengan pasien, dan setelah meninggalkan lingkungan pasien (Emergencies, 2009).

Perawat dalam memutus rantai infeksi memiliki peranan yang besar, salah satunya dengan memberikan edukasi kepada setiap pengunjung rumah sakit salah satunya kepada penjaga pasien yang senantiasa ada dekat pasien dan membantu dalam perawatan pasien selama di rumah sakit.

\section{METODE}

Kegiatan ini dilakukan di ruang penyakit dalam RSUD dr. Samet Garut. Kegiatan ini diikuti oleh 25 peserta. Metode yang digunakan yaitu edukasi masyarakat melalui metode penyuluhan langsung

1. Memberikan edukasi kepada dengan metode penyuluhan

2. Melakukan praga cuci tangan dengan menggunakan media music.

3. Evaluasi dengan instrument kuesioner dan observasi.

\section{HASIL DAN PEMBAHASAN}

Kegiatan pengabdian masyarakat yang dilakukan terdiri dari tiga tahapan yaitu: persiapan, pelaksanaan, dan evaluasi. Pada tahapan persiapan, kegiatan yang dilakukan adalah membuat perencanaan seperti menyusun SAP (Satuan Acara Penyuluhan), media edukasi bentuk power point, video dan leaflet yang akan diberikan kepada keluarga penjaga atau keluarga pasien. Pada tahapan ini juga disusun instrumen yang berguna untuk mengevaluasi materi yang disampaikan. Instrumen terdiri dari 10 pertanyaan yang mencakup pengetahuan tentang infeksi, pencegahan infeksi, manfaat cuci tangan, langkah-langkah cuci tangan, serta momen wajib cuci tangan. 
Tabel 1. Distribusi Frekuensi Pengetahuan pada keluarga penjaga pasien tentang hand Hygine sebelum edukasi

\begin{tabular}{llcc}
\hline No & Pengetahuan & Jumlah & $\begin{array}{c}\text { Persentase } \\
(\%)\end{array}$ \\
\hline 1 & Baik & 6 & 30 \\
2 & Cukup & 14 & 70 \\
3 & Kurang & 0 & 0 \\
& Total & $\mathbf{2 5}$ & $\mathbf{1 0 0}$ \\
\hline
\end{tabular}

Dari tabel 1 dapat diketahui pengetahuan peserta sebelum dilakukan edukasi, dari 25 peserta sebagian kecil (30\%) peserta sudah memiliki pengetahuan yang baik dan sebagain besar memiliki pengetahuan yang cukup.

Tabel 2. Distribusi Frekuensi Pengetahuan pada keluarga penjaga pasien tentang hand Hygine setelah edukasi

\begin{tabular}{llcc}
\hline No & Pengetahuan & Jumlah & $\begin{array}{c}\text { Persentase } \\
(\%)\end{array}$ \\
\hline 1 & Baik & 15 & 75 \\
2 & Cukup & 5 & 25 \\
3 & Kurang & 0 & \\
& Total & $\mathbf{2 0}$ & $\mathbf{1 0 0}$ \\
\hline
\end{tabular}

Tabel 2 menunjukkan bahwa pengetahuan peserta setelah dilakukan edukasi, dari 20 peserta sebagian besar $(75 \%)$ memiliki pengetahuan yang baik dan sebagian kecil (25\%) masih memiliki pengetahuan yang cukup. Dari hasil pengabdian masyarakat yang sudah dilakukan, pemberian edukasi mampu meningkatkan pengetahuan pasien mengenai hand hygiene.

Pengetahuan merupakan sekumpulan informasi yang terbentuk melalui proses pemaparan dengan obyek tertentu melaui stimulasi panca indra (Islam \& Khan, 2017; Sunarti \& Patimah, 2019). Pengetahuan merupakan salah satu faktor yang mempengaruhi perilaku seseorang. Perilaku yang didasari dengan pengetahuan akan bersifat langgeng dibandingkan dengan perilaku tanpa didasari dengan pengetatahuan (Khumayra \& Sulisno, 2012). Tujuan akhir dilakukannya pendidikan kesehatan ini adalah diharapkan masyarakat memiliki perilaku yang mengarah pada peningkatan derajat kesehatan.

Edukasi merupakan langkah awal untuk meningkatkan perilaku yang lebih baik, memberikan dukungan dalam pengambilan keputusan (Funnell et al., 2011). Beberapa hal yang perlu diperhatikan dalam edukasi adalah komunikasi. Komunikasi sarana bagaimana informasi itu dikemas sebaik mungkin agar menjadi dasar dalam pembentukan perilaku yang melekat bagi penerima informasi. Kemampuan dan keterampilan komunikasi yang baik dan benar serta efektif merupakan kemampuan yang penting yang harus dimiliki perawat dalam menjalankan perannya sebagai educator, dimana komunikasi dapat menjalin kerjasama dalam mencapai tujuan yang diharapkan (Fayram, 2003; Patimah, Megawati, \& Suryawantie, 2018).

\section{SIMPULAN}

Kegiatan pengabdian pada masyarakat yang sudah dilakukan di RSUD dr. Slamet Garut ini sudah dilaksanakanan dan kegiatan berjalan lancar sesuai dengan rencana yang disudah dipersiapkan sebelumnya. Berdasarkan hasil pengabdian masyarakat, terdapat peningkatan knowledge dimana jumlah peserta yang memiliki pengetahuan baik meningkat dari $30 \%$ menjadi $75 \%$. Media pembelajaran yang sudah dipersiapkan berupa leflet disosialisasikan ke seluruh pengunjung rumah sakit melalui media poster yang di tempel di ruangan khususnya ruangan penyakit dalam dan bedah.

\section{DAFTAR PUSTAKA}

Arefian, H., Hagel, S., Fischer, D., Scherag, A., Brunkhorst, F. M., Maschmann, J., \& Hartmann, M. (2019). Estimating extra length of stay due to healthcareassociated infections before and after implementation of a hospital-wide infection control program. PLOS ONE, 14(5), e0217159.

Emergencies, H. (2009). IC Module Plan.

Fayram, E. (2003). Nurse as Educator: Principles of Teaching and Learning for Nursing Practice, 2nd ed. The Journal of Continuing Education in Nursing, 34(6), 281-282. https://doi.org/10.3928/00220124-20031101-12

Haque, M., Sartelli, M., McKimm, J., \& Abu Bakar, M. (2018). Health care-associated 
infections - an overview. Infection and

Drug Resistance, 11, 2321-2333.

https://doi.org/10.2147/IDR.S177247

Islam, Shiful and Khan, Rajib Hossain, Exploring the Factors Affecting Knowledge Sharing Practices in Dhaka University Library.(2014). Library Philosophy and Practice (e-journal). 1095.

Khumayra, Z. H., \& Sulisno, M. (2012). Perbedaan pengetahuan dan sikap perilaku hidup bersih dan sehat (phbs) antara santri putra dan putri. Jurnal Nursing Studies, 1, 197-204. Retrieved from Boarding School can also be a threat of disease transmission if not properly managed

Patimah, I., Megawati, S. W., \& Suryawantie, T. (2018). Efektivitas Metode Pembelajaran Cooperative Learning Terhadap Kemampuan Komunikasi pada Mahasiswa. Jurnal Pendidikan Keperawatan Indonesia, 4(1), 86. https://doi.org/10.17509/jpki.v4i1.12347

Sunarti, N., \& Patimah, I. (2019). Hubungan Tingkat Pengetahuan Dengan Upaya Pengendalian Tekanan Darah Pada Penderita Hipertensi Di Wilayah Kerja Puskesmas Karangmulya Kecamatan Karangpawitan Kabupaten Garut: Journal of Midwifery and Nursing, 1(3), 7-11. Retrieved from https://iocscience.org/ejournal/index.php/ JMN/article/view/241

WHO Evidence for Hand Hygiene Guidelines. (n.d.). 